\title{
Aproximación a la esencia del sufrimiento
}

\section{The essence of suffering}

\section{F. Torralba}

\section{RESUMEN}

En este artículo, se pretende explorar la esencia del sufrimiento a partir de la filosofía de santo Tomás de Aquino. El autor plantea la definición de sufrimiento $\mathrm{y}$, posteriormente, los tipos y formas de padecimiento que puede sufrir el ser humano.

Palabras clave. Sufrimiento. Tristeza. Santo Tomás.

\section{ABSTRACT}

This article explores the essence of suffering on the basis of the philosophy of Saint Thomas of Aquinas. The author sets out the definition of suffering and, subsequently, the types and forms of suffering that the human being can undergo.

Key words. Suffering. Sadness. Saint Thomas.

An. Sist. Sanit. Navar. 2007; 30 (Supl. 3): 23-37.

Institut Borja de Bioètica. Universidad Ramon Llull. Barcelona.

\section{Correspondencia:}

D. Francesc Torralba Institut Borja de Bioética C/ Santa Rosa, 39-57, $3^{\mathrm{a}}$ planta 08950 Esplugues (Barcelona)

Tfno. 936006106 e-mail: ftorralba@ibb.hsjdbcn.org 


\section{DIFÍCIL DEFINICIÓN}

Médicos, biólogos y científicos no se ponen de acuerdo cuando se trata de definir qué es el sufrimiento. Es curioso que un hecho tan banal y universal como el dolor, al que todo el mundo considera conocer y poder identificar, sea tan difícil de definir satisfactoriamente. En un diccionario considerado para muchos una autoridad se puede leer que el sufrimiento es una sensación penosa causada por una excitación violenta de las terminaciones cutáneas o viscerales de fibras nerviosas especializadas. Como podemos ver, esta definición de dolor se ciñe al ámbito fisiológico del individuo.

La IASP (Internacional Association for the Study of Pain) ha adoptado la siguiente definición: "Sensación y emoción desagradables asociadas a lesiones de los tejidos, presentes o potenciales, o presentadas en tales términos». A pesar de su extensión y la evidente intención de no restringir el campo semántico, esta definición continúa estando centrada en el carácter desagradable del dolor, y no en el hecho esencial y característico de este factum.

Se podría describir el sufrimiento como el efecto del dolor, aunque las exigencias del lenguaje nos obligan a utilizar ambas palabras indistintamente para evitar reiteraciones frecuentes. Algia sería un sinónimo perfecto, pero esta palabra ha tomado un carácter ligeramente pedante y se utiliza para denominar dolores muy localizados, como la cefalgia para los dolores de cabeza.

Uno se pregunta: ¿qué es exactamente el dolor? ¿Una sensación, o una emoción? ¿Una emoción relativa a una sensación?, o más bien, recuperando la fórmula de la IASP, ¿una sensación y una emoción? La pregunta queda sin respuesta.

Nuestra intención es aportar aquí una definición de carácter general y no exclusiva, una definición esencial, de carácter filosófico, no médico, ni fisiológico, una definición que incluya las aproximaciones científicas, éticas y religiosas. A partir de esta definición podremos inserir todas las formas posibles de sufrimiento: externas e internas, físicas y anímicas.
Toda definición es, a pesar de todo, limitada. El contacto con quienes sufren pone de manifiesto el inmenso vacío que separa el discurso sobre el dolor y los enfermos que lo sufren en propia carne. Hechas estas consideraciones propedéuticas, adoptamos la definición de un pensador del siglo XIII, santo Tomás de Aquino.

\section{APROXIMACIÓN FILOSÓFICA. COMENTARIO A SANTO TOMÁS}

Santo Tomás considera que el dolor exige dos cosas: "alcanzar un mal -que es mal porque nos priva de un bien-y la percepción de este logro" (S. Th., I-II, 1. 35 a. 1). En efecto, todo sufrimiento para ser sufrimiento necesita cumplir dos condiciones: en primer lugar el logro de un mal y en segundo lugar la percepción de este logro (coniunctio alicuius mali et perceptio huiusmodi coniunctionis). Ambas condiciones son necesarias y suficientes.

El mal, en la metafísica de santo Tomás, es un ente de razón y no un ente real $(S$. Th., I 1.48 a. 2 ad 2), cosa que significa que no tiene realidad ontológica, sino que es una privación de bien ( $S$. Th., I q. 13 a. 10), una imperfección. El mal no es algo existente, es decir, una naturaleza, o un espíritu, ni está en las cosas existentes como una parte de su perfección, más bien al contrario, está como privación de bien, como privación de ser (S. Th., I q. 48 a. 1).

Así lo expresa en el Compendio de Teología: "Tenemos que considerar que, así como con el nombre de bien entendemos la perfección del ser, con el nombre de mal no entendemos nada más que la privación de esta perfección. Ahora bien, como que la privación propiamente dicha es la privación de un bien debido a que le pertenece en un tiempo y de una manera determinada, es evidente que denominamos mala una cosa porque está falta de una perfección que debe tener. Por ejemplo, si a un hombre le falta el sentido de la visión, es un mal para él, pero no lo es para una piedra, porque la visión no es propia de ésta». (\& 223).

El mal no tiene una realidad física, ni es un principio autónomo que se opone al bien, como defendían los maniqueos, sino que es justamente ausencia de bien. Como 
dice santo Tomás: «El mal no puede existir por sí (per se) dado que no tiene esencia (S. C. G., III cap. 11). Los entes participan del ser (esse) según su naturaleza esencial. Hay algunos que participan del ser con más plenitud ontológica porque están dotados de entendimiento y de voluntad. Otros, en cambio, participan muy ínfimamente. Existe una cadena jerárquica de los entes. A cada escalón le corresponde un determinado grado o nivel de bien. El ente tiende a alcanzar este bien que está a su alcance, movido por el dinamismo perfectivo (J. Bofill). Si no consigue gozar de este bien que le corresponde por naturaleza, sufre. Esta privación de bien es el mal.

Así lo explica santo Tomás en la Suma contra los gentiles: «El mal está en la sustancia cuando a ésta le falta lo que tiene que tener por naturaleza, y por esto no es mal que un hombre no tenga alas, porque no le pertenecen naturalmente; y si no tiene cabellos rubios, esto no es un mal, ya que, aunque le corresponderían por naturaleza, no es necesario que tenga. Sería, en cambio, un mal si no tuviera manos, ya que por naturaleza tiene que tenerlas, si es perfecto; pero en cambio, esto no sería un mal para un pájaro. Toda privación, por tanto, tomada estricta y propiamente, es de algo que se tiene que tener por naturaleza. Así, pues, la privación entendida de esta forma, siempre incluye la razón del mal (ratio mali) (L. III, cap. 6).

Santo Tomás distingue un doble género de mal: «Siendo el mal una privación y un defecto, según se ha dicho antes, este defecto puede surgir en una determinada cosa no sólo en referencia a su naturaleza, sino también cuando su relación es ordenada a un fin. Por consiguiente, el mal se predica de dos formas, a saber, según un defecto en la propia cosa, como la ceguera es un mal en el animal y según un defecto en la acción, como la cojera, que representa una acción con un defecto" (Compendio, $\&$ 119). Por tanto, el mal considerado como privación del bien puede residir en dos lugares: en la propia naturaleza del ente, o bien en su relación con un determinado fin. En ambos casos el mal causa sufrimiento en el sujeto.

La percepción de esta imperfección, de esta privación de bien, sea por defecto pro- pio de la naturaleza, como la sordera o la ceguera, sea en la relación respecto al fin, es decir, al fracaso, causa el sufrimiento.

Santo Tomás aún hace una segunda distinción. Las cosas tienden a un fin, que es su bien; pero también pueden seguir una conducta desordenada y no dirigirse al bien que les es propio. Es decir, el sujeto puede desviarse del fin que le está reservado, sea de forma natural, sea de forma voluntaria o intencional. Por ejemplo, la naturaleza obra mal cuando no conduce la cosa engendrada a la disposición y forma adecuadas, como cuando en la naturaleza nacen monstruos. La percepción de este mal causa dolor. Pero esta desviación respecto al fin puede ser también intencional, como, por ejemplo, cuando un médico, en lugar de restablecer la salud, conduce un enfermo hacia la muerte. En este caso hay un alejamiento del fin de forma intencional. Es el mal de la culpa. Y este mal también produce sufrimiento. Por tanto, todo género de mal, sea natural o voluntario, produce, en último término, sufrimiento.

Ahora bien, el dolor siempre es dolor de un sujeto que lo sufre. No existe el sufrimiento en sí mismo considerado, in gene$r e$, sino que siempre se refiere a un ente que percibe el mal. Por tanto, no todo mal causa dolor, sino tan sólo el que recae sobre un sujeto capaz de percibirlo como tal. Una roca no percibe el mal, porque non está dotada de sentidos, ni internos ni externos; por tanto, tampoco sufre. Tan solo aquel ser capaz de percibir el mal puede sufrir. El animal sufre en la medida en que siente un determinado mal: una indisposición fisiológica, una privación de sus facultades... El hombre sufre en la medida en que percibe un mal, que puede ser de diferentes formas: físico (corporal), espiritual (anímico) y puede ser producido de una manera natural (un dolor de muelas), o de una forma voluntaria.

Una cosa puede ser objeto de una determinada imperfección, pero no percibirla. Para que haya dolor tiene que haber mal, y percepción de este mal. El hombre puede estar realizando una mala operación, pero al no percibir esta falta de perfección, no sufre. No todos los entes perciben el mal de la misma forma. Hay algunos 
que son más sensibles y perfeccionistas; hay otros, en cambio, que son más opacos al mal propio o ajeno. El sufrimiento es, en el fondo, una cuestión de percepción. Una imperfección de la naturaleza, un determinado desorden o privación de bien se puede percibir de forma muy distinta según el sujeto que lo esté observando o sufriendo. Hay individuos que tienen más tendencia a sufrir porque son más sensibles al mal, a la imperfección. Otros, en cambio, no matizan tanto, y a veces, cometen una acción desordenada, que ni siquiera perciben como tal.

Tal y como vemos, pues, el sufrimiento siempre se refiere a un sujeto. Pero, ien qué lugar del sujeto incide el dolor? En el apetito sensitivo o en el apetito intelectivo. Depende de la naturaleza del mal. Si el mal es corporal, entonces el dolor reside en el apetito sensitivo. Si el mal, en cambio, es de origen espiritual, entonces el dolor pertenece al apetito intelectivo. El dolor del animal sólo puede residir en el apetito sensitivo porque no tiene espiritualidad.

Dice santo Tomás por lo que respecta a esta cuestión: "Decimos con toda propiedad que el dolor es una pasión, en la medida en que es en el apetito sensitivo, de la misma forma que las molestias corporales son denominadas propiamente pasiones del cuerpo. En este sentido, Agustín dice que el dolor es especialmente una enfermedad (S. Th., I-II, q. 35 a. 1).

\section{SUFRIMIENTO Y DESEO DE UNIDAD}

Todos los entes, incluso aquellos faltos de entendimiento, tienden por naturaleza al bien (Quomodo appetunt bonum etiam quae cognitatione carent) (S. C. G., III cap. 24). Las cosas tienden a buscar su propio bien. El ente puede llegar a alcanzar este bien, pero también puede no conseguirlo. Si consigue el bien y lo percibe como tal, entonces llega al estado de placer, ya que el placer es, según santo Tomás, alcanzar el bien y la percepción de este logro.

Ahora bien, si no consigue alcanzar el bien, entonces permanece en la privación de este bien y la privación de este bien es el mal. La percepción de este mal es el dolor. Por tanto, el hombre, en la medida en que busque el bien y no consiga alcanzarlo, caerá en el sufrimiento. O dicho de otra forma, cuando la naturaleza apetezca una cosa como bien y sea privada de ésta, entonces se resentirá, cosa que provocará la pasión del dolor en el apetito sensitivo o intelectivo ( $S$. Th., I-II q. 35 a. 1).

Por tanto, el sufrimiento está íntimamente vinculado a la búsqueda del bien. Si el hombre no buscara su bien, tampoco no percibiría la privación de este bien y no sufriría. Pero esto es del todo imposible, porque el hombre, por propia naturaleza (per naturam), tiende a buscar su bien, tanto físico como espiritual. Por consiguiente, el hombre, como cualquier otro ente capaz de percibir, está totalmente abierto a la posibilidad del mal y del dolor.

Torras i Bages interpreta la tesis de santo Tomás considerando que el deseo de unidad es la causa del dolor. Dice el sabio de Vic: "Los hombres nos sentimos incompletos, y el amor de la unidad tiene unas exigencias tan poderosas que siempre que no hallamos desposeídos de ella, cuando echamos a faltar alguna cosa siempre que un obstáculo nos impide, experimentamos como una amputación en nuestra naturaleza y no sosegamos y sufrimos como a quien le falta una parte de vida..." (Ciència del patir, p. 15).

En efecto, el hombre tiende a la unidad, a la armonía, a la plenitud. En este caminar hacia la unidad tropieza con frecuencia con obstáculos e inconvenientes que hacen de su vida un calvario. El deseo de unidad y de paz es causa del dolor. Si el hombre no tuviera este anhelo, tampoco no sentiría su ausencia. Pero esto es imposible. El apetito de armonía es, según Torras i Bages, el motor del dolor.

\section{EXCURSUS SOBRE LA NO-VOLICIÓN}

Algunos pensadores y místicos orientales han considerado que la clave de la felicidad está en el no-desear, en la no-volición. Si no se desea nada, tampoco no se sufre la privación de ningún bien. La clave de la bienaventuranza humana radica en la quietud, en la calma, en el aislamiento del mundo, de la praxis y de las pasiones.

Lo podemos leer en el Tao te King, de Lao Tse: "Es por esto que dice el santo: si 
yo practico el no-actuar, el pueblo se transforma a sí mismo. Si yo amo la quietud, el pueblo se corrige a sí mismo. Si yo no alimento ningún deseo, el pueblo vuelve de sí mismo a la simplicidad». (\& LVII). Y añade en otro lugar: "Alcanza la suprema vacuidad y permanece en quietud; frente al hormigueo airado de los seres no contemples otra cosa que su retorno. Los seres diversos del mundo volverán a su raíz. Volver a la raíz es instalarse en la quietud; instalarse en la quietud es volver a encontrar el orden; volver a encontrar el orden es conocer lo constante; conocer lo constante es la iluminación (\& XVI).

En la tradición occidental, la tesis de la no-volición y la quietud de las pasiones han sido defendidas por la escuela estoica. $\mathrm{Si}$ bien es cierto que uno y otro planteamiento no pueden identificarse, sí es cierto que existe una afinidad de ideas por lo que comporta a la figura del sabio. El sabio estoico es el ideal de humanidad, el paradigma de la tranquilidad, representa la culminación de la apatheia. Los estoicos pensaban que la última felicidad del hombre consistía en la tranquilidad de espíritu, en apaciguar las paciones, en amortiguar los instintos, en definitiva, en la no codicia de un fin.

Dice nuestro Séneca: «El hombre tiene que ser incorruptible y no debe dejarse vencer por las cosas externas, tiene que estar atento en sí mismo, seguro de sus fuerzas, preparado para la suerte y la desgracia, tiene que ser artífice de la propia vida, su confianza no tiene que estar falta de ciencia, ni su ciencia, de firmeza: tiene que ser constante en sus propósitos..." (De la brevedad de la vida, \& 8).

A pesar de admitir el noble valor de la ética estoica y, también, su carga aleccionadora, hay que decir que esta negación del deseo que predica es contraria a la naturaleza, sea humana, sea animal. Todo ente, por el mero hecho de ser ente, tiende a un fin y este fin es su bien. La dinámica teleológica es intrínseca al mismo ser natural. La planta busca la luz, el animal busca el alimento, el hombre busca su conservación y su perfección espiritual.

Todo agente natural busca su bien (Omne agens agit propter bonum) (S.C.G., III cap. 3). El ente natural tiene, pues, un connatus hacia el fin. Puede tender hacia él solamente per natura, como los entes irracionales, que no están dotados de entendimiento, o puede tender hacia el fin por naturaleza y además de forma voluntaria, como es el caso del hombre. Pero en ambos casos, la realidad siempre es teleológica, es decir, va orientada hacia un fin, hacia un puerto.

Por tanto, el sufrimiento es inherente a la vida, no sólo por causa de las privaciones naturales, sino por causa del fin. Si hay un fin, existe, inevitablemente, el sufrimiento.

\section{SUFRIMIENTO, FILOSOFÍA Y VIDA}

Es interesante ahondar en esta concepción del dolor y compararla con otras concepciones. Según santo Tomás, el dolor no es el elemento esencial ni definitorio de la vida, como postulaban los románticos alemanes y el propio F. Nietzsche. A pesar de ello, Santo Tomás reconoce que el vivir comporta sufrimiento por sí mismo. La vida no es un campo en el que todo transcurre con suavidad. Nada de eso. La vida está llena de dolor y santo Tomás no olvida este componente vital. Por eso describe el dolor como la percepción del mal que hay en la vida.

Ahora bien, el mal no es un elemento única y exclusivamente negativo. Sí que es un elemento privativo, pero su ser es el bien. La razón del sufrimiento no radica en él mismo sino que radica en un bien. El mal, y por tanto, el dolor no tienen ser real, sino que es un ente mental que indica falta de ser, falta de plenitud. A través del dolor nos damos cuenta de que no somos perfectos, que no todos los fines están a nuestro alcance. Nos damos cuenta, al fin y al cabo, de que la vida es algo más serio que un juego de pulsiones (Freud), o una estrategia de intereses (Baudrillard). El dolor pone de manifiesto que no somos dioses, sino individualidades que tendemos a un determinado fin que cuesta alcanzar.

Como dice Torras i Bages comentando a santo Tomás: «el sufrimiento o la contrariedad son un ingrediente tan íntimo en la presente vida terrenal, que sin él se vuelve asquerosa e incluso insoportable. No habría 
nada peor, si esto fuera posible, que un hombre que no tuviera ningún problema, ninguna contrariedad, que todo fuera a su placer, que nadie le contradijera, que todo el mundo le diera la razón, que todo el mundo le obsequiara, que en el momento de tener un gusto, enseguida experimentara su satisfacción; quien viviera en esta atmósfera, se ahogaría; y todos sabemos casos de suicidio en hombres asqueados de vivir por no poder soportar una vida en que los gozos se convertían en ascos por la monotonía de la satisfacción". (Ciència del patir, p. 14).

Si bien el hombre rechaza por naturaleza el dolor y tiende a alejarse de él, cabe decir que una vida sin sufrimiento, sin sacrificio, sin esfuerzo, resulta insípida, aburrida y pesada. El sufrimiento es un ingrediente íntimo de la vida humana. Una vida sin sufrimiento se convierte en una monótona melodía, en una línea continua e invariable en la que no existe ninguna curva, ninguna desviación. El dolor, por tanto, también tiene su lado positivo, y a pesar de que el hombre se aleje del sufrimiento y trate de evitarlo, también hay que decir que el sacrificio es la sal de la vida. El hombre que lo tiene todo, que no le falta nada, que complace cómodamente todos sus deseos, que no busca nada porque ya está harto de todo, se ahoga en su mundo autosuficiente y se hunde en la cueva del tedio.

Esta misma idea la expresa también un autor actual, Daniel Innerarity. Dice así: "Un futuro sin riesgo ni azares, una carrera segura, una vida cotidiana exenta de tensión figuran entre las condiciones más habituales del aburrimiento. En este mundo, quien tiene todo lo que quiere, raya la desesperación" (Libertad como pasión, Eunsa, Pamplona, 1992, p. 85). Como dice también Jankélévitch, la facilidad excesiva aburre tanto como la dificultad exagerada desanima.

Es interesante reiterar la tesis de que el mal no tiene una entidad propia, sino que brota del bien. Si no hubiera bien, tampoco no habría mal, porque el mal es privación, es negación de bien. Así lo explica santo Tomás: "No puede existir nada que sea esencialmente malo, porque siempre hace falta que un mal esté fundamentado en otro sujeto bueno; y por tanto, no puede existir nada que sea un mal en grado sumo, como hay un bien en grado sumo, que es esencialmente bueno" (Compendio, \& 117).

Por consiguiente, santo Tomás describe un universo fundamentado en el ser y en el bien. Pero es cierto que en el mundo hay indigencia y sufrimiento. Este sufrimiento brota de la percepción del mal, pero el mal no se opone al bien, tal como hemos visto, sino que es privación de este bien. Por tanto, es probable que nuestro mundo no sea el mejor de los mundos posibles, tal como defendía Leibniz en su Teodicea, y seguramente no es absolutamente perfecto, ya que no se identifica con Dios, como defendía Spinoza en su Ética (Deus sive natura sive substantia), sino que más bien es un mundo que tiende a la perfección, que peregrina hacia el Bien. Y esta tendencia no siempre se convierte en acto. La privación de este fin causa sufrimiento. Es el sufrimiento del mundo.

Nos encontramos, pues, frente a una interpretación filosófica que parte de la plenitud del ser y de la experiencia real y cotidiana del mal. Es una hermenéutica racional equilibrada y fiel a la realidad de las cosas. Desde esta Weltanschaaung, el mal no es la razón última del mundo, como defendía Schopenhauer, sino una privación de bien. Y por otra parte, esta cosmovisión tampoco no cae en un optimismo ingenuo, tan típico de la mentalidad ilustrada, que tiende a tapar y oscurecer la realidad del sufrimiento y a dibujar un universo armónico en el que cada pieza funciona a la perfección. Ambos elementos, la perfección del ser y la imperfección del mal, se encuentran vinculados a la existencia, pero cada uno interactúa desde su status ontológico.

\section{SUFRIMIENTO Y TRISTEZA}

A continuación, santo Tomás hace una distinción muy acertada entre dos conceptos que, a veces, tomamos como sinónimos pero que no son exactamente lo mismo. El autor de la Suma distingue entre dolor y tristeza.

Dice lo siguiente: «El placer y el dolor pueden tener su origen en una doble aprehensión, es decir, en la aprehensión de los sentidos exteriores o en la aprehensión 
interior de la inteligencia o de la imaginación. La aprehensión se extiende a más objetos que la aprehensión exterior, dado que lo que es objeto de la aprehensión exterior lo es también de la interior pero no al revés. Denominamos alegría solamente el placer causado por una aprehensión interior, como ya hemos dicho. Igualmente, denominamos tristeza solamente al dolor causado por una aprehensión interior». (S. Th., I-II, q. 35 a. 2).

El dolor, tal como lo hemos visto con anterioridad, es la percepción de un mal. La aprehensión del dolor puede ser de dos tipos: interior o exterior. La aprehensión exterior es la que tenemos a través de los sentidos externos, básicamente del tacto (una quemada, un pinchazo...). La aprehensión interior, en cambio, viene propiciada por las facultades internas del sujeto, la inteligencia y la imaginación. Es aquel dolor que se origina por el pensamiento, por la reflexión, por la meditación, por el recuerdo o la simple imaginación. Santo Tomás considera que la aprehensión interior tiene un alcance más amplio que la aprehensión exterior. Es cierto, ya que la aprehensión interior incluye la exterior (en la medida en que la recordamos o simplemente la pensamos) y contiene otras que no vienen motivadas por los sentidos externos. La aprehensión interior de un dolor es lo que denominamos tristeza. Una persona está triste cuando aprehende interiormente un dolor.

Por tanto, dolor y tristeza no se identifican totalmente. El dolor es siempre la aprehensión de un mal, pero esta aprehensión puede ser únicamente externa y éste es el caso del dolor propiamente dicho, o quizás también interior y en este caso estamos tratando de la tristeza. Por eso, concluye santo Tomás diciendo que la tristeza es una especie de dolor (tristitia est quedam species doloris).

\section{TRISTEZA, SUFRIMIENTO INTERIOR}

La tristeza se refiere más propiamente a un dolor interior. Una persona que ha sufrido una desgracia familiar está triste, y en cambio, no sufre ningún dolor externo. La tristeza está motivada por la inteligencia y la imaginación. Si el hombre no fuera capaz de pensar, meditar y reflexionar sobre su vida y sus actos tampoco sentiría tristeza. La tristeza solamente es posible en un ser inteligente e imaginativo. La aprehensión externa del dolor es universal a todos los animales dotados de sentidos. La aprehensión interior del dolor, en cambio, sólo es propia del ser inteligente, racional e imaginativo. Este dolor interior que es la tristeza afecta a cualquier sujeto globalmente considerado y produce en él unos efectos mucho más graves y problemáticos que el dolor externo.

Dice santo Tomás a continuación: "Los sentidos exteriores sólo perciben lo que es presente. La facultad cognoscitiva interior, en cambio, puede percibir el presente, el pasado y el futuro. Por eso puede haber tristeza del presente, del pasado y del futuro, mientras que sólo podemos sentir dolor corporal de lo que es presente». (ibidem).

En efecto, un pinchazo, un dolor de riñones, un dolor de cabeza, dura mientras dura el dolor, y cuando el mal deja de incidir sobre el órgano en cuestión, entonces también desaparece el dolor. El dolor que aprehendemos por los sentidos exteriores dura lo que dura el mal y basta. El dolor interior, en cambio, non tiene límites de duración. El pasado puede ser objeto de tristeza. Un mal ocurrido hace mucho tiempo puede aflorar de nuevo en la consciencia y producir tristeza e incluso remordimiento. La anciana recuerda la tragedia de la guerra civil, la muerte de su hija y de su marido. El dolor que sufrió en aquel tiempo tan lejano vuelve a Omar forma en su presente histórico y le produce tristeza.

El miedo a un mal que con toda probabilidad tiene que suceder en el futuro también produce tristeza. El hombre está triste cuando su futuro es incierto, sea por causas laborales (dado que tiene un contrato basura y le despedirán), sea por causas de salud (por el desarrollo de una enfermedad incurable), o por razones afectivas (el inminente viaje del esposo). En todos estos casos, el hombre tiene la capacidad de avanzar mentalmente el futuro y de preverlo. Esta previsión de un futuro negro entristece el hombre y le causa dolor interior.

De todos los acontecimientos que le aguardan en el futuro hay uno inevitable y 
universal que le preocupa de forma alarmante: es el misterio de la muerte. La muerte, que significa la privación definitiva y total de la vida y del bien, causa una profunda tristeza. Y es profunda porque significa el aniquilamiento integral de todo bien, de toda naturaleza, de toda vida. Como dice M. Horkheimer, "la muerte es el último acto de la vida». Mientras hay vida, hay posibilidad, hay esperanza, hay futuro. Con la muerte se acaba cualquier posibilidad de realización. Sólo con la creencia religiosa o moral (como en el caso de I. Kant) en una vida post mortem el hombre puede aliviar este dolor interior.

El animal por otra parte, no tiene capacidad de avanzar su futuro y por esto no se inquieta por la muerte ni por su aniquilación. Vive inmerso en la temporalidad y en la inmediatez de la vida instintiva. El hombre, en cambio, es un animal histórico y esto significa que tiene consciencia de su pasado, de su presente y de su futuro. A través de la inteligencia, de la memoria y de la imaginación puede viajar a los tres vértices del tiempo y configurar ideas sobre estos estadios.

En consecuencia, el vínculo entre dolor y tristeza puede formularse de la siguiente forma: "Si por dolor entendemos el dolor corporal, como suele hacerse, entonces, de acuerdo con la distinción entre aprehensión interior y exterior, el dolor se diferencia de la tristeza oponiéndose a ella; aunque, por lo que se refiere a los objetos, el placer le atañe más que no el dolor corporal. En cambio, si damos el dolor un sentido amplio, el dolor es un tipo de tristeza, como se ha dicho". (Ibídem).

\section{FORMAS DE TRISTEZA}

Hay diferentes especies de tristeza. Santo Tomás considera cuatro formas posibles, de las que tres, aunque de forma dispersa, ya habían sido analizadas por Aristóteles. El estagirita distinguía, en primer lugar, la tristeza por lo que es miserable. Esta tristeza se produce por la miseria, es decir, por la escasez de bondad, sea espiritual, sea material (Retórica 2, 8). Existe, en segundo lugar, la tristeza del envidioso (Ética a Nicómaco 2, 7). El envidioso está triste porque le falta un bien que tiene su vecino o su compañero. Él quiere tener este bien, pero no le es posible. La envidia causa en él tristeza. En tercer lugar, existe la tristeza del angustiado (Ética a Nicómaco 4, 2). El angustiado es aquel hombre que teme perder un bien, o teme que le será tomado en un futuro próximo. La incertidumbre del bien le produce angustia y la angustia genera, a la vez, tristeza.

Santo Tomás delimita los tipos de tristeza en base a diferentes criterios. El primer tipo de tristeza es la que es producida por un mal propio (a. 35 a. 8). De hecho, el objeto propio de la tristeza es un mal propio, es decir, por una privación que nos afecta personalmente. Estamos tristes cuando sufrimos un determinado mal. Pero la tristeza también puede tener otro origen, a saber, el mal ajeno. Desde este punto de vista, podemos hablar de tres tipos distintos de tristeza. Podemos estar tristes por el mal que sufre una persona que conocemos y amamos, y esta tristeza recibe el nombre de compasión. La compasión es la tristeza por el mal ajeno pero considerado como propio. Pero también podemos pensar que este mal no nos es propio y que no es ningún mal sino un bien ajeno; un bien ajeno, sin embargo, que nosotros estimamos como un mal propio. Esta especie de tristeza es el caso de la envidia. Y por último, el efecto propio de la tristeza consiste en hacer que el apetito huya de algo. Aparece así la ansiedad que acapara totalmente el ánimo que no halla refugio en ninguna parte, por cuya razón se denomina también angustia. Este efecto puede ser tan grande que paralice incluso los miembros exteriores. Éste es el caso del desánimo.

En definitiva, podemos diferenciar, siguiendo a santo Tomás, cuatro formas de tristeza. La primera, producida por un mal propio, la segunda (la compasión), y la tercera (la envidia) causadas por un mal ajeno, y la última causada por el efecto que el mal produce en el apetito (la ansiedad).

\section{LAS RAÍCES DEL SUFRIMIENTO}

Siguiendo el hilo discursivo de la filosofía de santo Tomás, vamos a ver, a continuación, las diferentes causas del sufrimiento. Todo agente tiene una determinada causa. Aristóteles y santo Tomás describen el uni- 
verso como un conjunto de entes regidos por un orden causal en el que todo lo que sucede tiene una razón concreta, tiene una finalidad específica. El mundo es un conjunto ordenado de elementos, no una simple multiplicidad, sino una multiplicidad unificada.

La inteligencia humana descubre en el mundo no una diversidad caótica de cosas o fenómenos, sino un cosmos, un inmenso conjunto de seres escalonados según su perfección, trabados los unos a los otros según diversas relaciones causales, que tomadas conjuntamente ofrecen una imagen unitaria y armónica. La unidad es anterior a la pluralidad y constituye su origen. Pero la diversidad no emana de la unidad como diversidad pura, sino constituyendo un ordo, una compositio o síntesis. Todo orden implica una distinción, implica que los seres se acomoden de diferente manera a un prototipo ideal que constituya su medida. La multiplicidad indiferenciada, lo que es meramente cuantitativo no puede ser sujeto de un orden, sino que el orden exige, constitutivamente, una jerarquía, es decir, el establecimiento de grados o clases.

Existe una ordenación de los seres en virtud de su mayor o menor perfección que viene en gran medida definida no sólo por los esquemas de un finalismo inmanente, sino también y muy en especial por un finalismo trascendente (Jaume Bofill). En el mundo cada ente tiene su lugar y su fin. Este orden no se refiere solamente al orden estático, sino que tiene que entenderse como el resultado de la finalidad y por consecuencia, como un orden dinámico. En el mundo todo sucede por una determinada razón. "Natura nihil facit frustra", la naturaleza no hace nada en vano, dice santo Tomás, siguiendo al estagirita.

Desde esta perspectiva, también el sufrimiento, como cualquier otra realidad, debe tener una determinada causa. Si bien el dolor no tiene una realidad física, ontológica, en la medida en que es la percepción del mal y por tanto, la percepción de una privación, también es lícito determinar una causalidad que lo propicia o lo hace posible.

Investigar las causas del sufrimiento significa investigar, en último término, las causas del mal, ya que el sufrimiento, tal y como lo hemos definido anteriormente, es la percepción del mal. ¿Por qué hay mal en el universo? ¿Qué lo hace posible? ¿Cuál es la causa del mal? ¿Cuál es su naturaleza? ¿Qué lugar ocupa en el orden del universo? En la Suma contra los gentiles, santo Tomás defiende que el mal no tiene una causa propia sino que tiene una causa accidental (non habeas causam per se, cuiuslibet tamen mali oportet esse causam per accidens) (III cap. 13). Para probar esta tesis, santo Tomás ofrece varios argumentos.

En términos generales se pueden describir de la siguiente forma: el mal es una cierta privación. La privación es un principio accidental en las cosas mudables, diferente de la materia y la forma, que son principios propios. Un principio propio tiene una causa propia, un principio accidental debe tener una causa accidental. Por tanto, el mal es causa accidental de las cosas.

O dicho de otra forma: un mal es un defecto de la causa, una falta de causa. A pesar de ello, no puede ser causa por si mismo, porque una cosa no es causa por lo que tiene de deficiente, sino por lo que tiene de entidad, ya que si fallara totalmente, no sería causa de nada. Por esta razón, el mal no tiene causa propia, sino que tiene una causa accidental.

Según santo Tomás, la causa del mal es, en último término, el bien (causa mali est bonum) (S.C.G., III cap. 10). El mal es privación y, desde este punto de vista, no es nada, no tiene entidad. Lo que no existe no puede ser causa de nada. Ahora bien, toda causa tiene que ser alguna entidad. Si el mal no es entidad, entonces no puede causar nada. Por tanto, si el mal tiene una causa pero no es entidad, esta causa no puede estar en él mismo, dado que él no es nada, sino que tiene que estar en la entidad, en el bien.

Santo Tomás añade aún otro argumento muy claro: "Todo lo que propia y naturalmente es causa de algo tiende a producir su propio efecto. Si el mal fuera causa de algo, tendría que producir su efecto, es decir, el mal. Y esto es falso, porque todo agente intenta el bien. Por tanto, el mal no es causa propia de nada, sino que lo es 
accidentalmente. Pero toda causa accidental se reduce a la causa propia, y únicamente el bien puede ser causa propia, pero el mal de ninguna forma. Así, pues, el mal está causado por el bien". (Ibidem).

Entendido el mal de esta forma, como causa impropia o accidental, es comprendido también perfectamente porque el mal sumo no puede existir (non est summum malum) (S.C.G., III cap. 15). Lo que existe accidentalmente es posterior a lo que existe por si. El mal existe accidentalmente, porque no tiene una intencionalidad ni una razón específica; por tanto, el mal no puede ser el primer principio ya que depende ontológicamente del bien. El mal sumo tendría que ser mal por propia esencia, como el bien es bueno por su esencia. Pero esto es imposible porque el mal no tiene ninguna esencia. Así pues, es imposible suponer un mal sumo que sea principio de todos los males.

Así lo expresa santo Tomás en el Compendio de Teología: «No puede existir nada que sea esencialmente malo, porque siempre es necesario que un mal esté fundamentado en otro sujeto bueno y, por tanto, no puede existir nada que sea un mal en grado sumo, como hay un bien en grado sumo, que es esencialmente bueno". (cap. 117).

Hecha esta distinción esencial entre causalidad propia y la causalidad accidental, vemos ahora las diferentes causas que hacen posible el mal. El autor de la Suma Teológica dedica un breve espacio de su magna obra a estudiar especulativamente las diferentes causas del sufrimiento $(S$. Th., I-II q. 36 a. 1-4). Distingue cuatro, que son las siguientes: en primer lugar, la pérdida de un bien o el advenimiento de un mal (bonum amissum vel malum coniunctum); en segundo lugar, la concupiscencia (concupiscentia); en tercer lugar, el apetito de unidad (appetitus unitatis), y finalmente, una potencia irresistible (potestas cui non potest resisti).

\section{La pérdida de un bien}

La pérdida de un bien (bonum amissum) que el sujeto goza en propiedad es siempre causa de sufrimiento ( $S$. Th., I-II q. 36 a. 1). El bien, que es lo que todas las cosas desean (bonum est quod omnia appetunt), tal como dice Aristóteles en la Etica (I, 1, 1094 ${ }^{a}$ ) se identifica con la perfección del ser. El mal, en cambio, se relaciona con la privación de esta perfección. La pérdida de un bien quiere decir, por tanto, la privación de una determinada perfección, sea de naturaleza física, espiritual o moral. La falta de una virtud o propiedad o capacidad del sujeto genera siempre sufrimiento. Esta privación, que no tiene entidad real, sí tiene entidad de razón.

En cierta forma la pérdida de un bien y el advenimiento de un mal son las dos caras de una misma moneda. El mal no es algo extrínseco que se engancha al sujeto. No es, tal como hemos dicho anteriormente, una realidad física, ni espiritual. Es un ente mental. Por esto es lícito afirmar que la pérdida de un bien y el advenimiento de un mal son dos cosas exactamente iguales. Pero el sujeto percibe esta pérdida del bien como una contrariedad, que significa con una cierta oposición. Por esto dice santo Tomás que el mal, aunque no tenga realidad ontológica, se comporta a la manera de un contrario.

Un hombre pasea por la calle, tropieza con una valla y queda paralítico. La parálisis es la pérdida de un bien, este bien era la capacidad de moverse, de trasladarse. Esta pérdida genera sufrimiento. Por otra parte, la parálisis también se puede interpretar como un mal adventicio, como un mal que le ha caído encima sin buscarlo. En cualquier caso, la pérdida de un bien o el advenimiento de un mal producen siempre sufrimiento. Y produce sufrimiento porque significa la falta de una perfección que el sujeto tenía en si mismo y que ahora, por un motivo accidental, ha perdido.

Cuando el bien que perdemos es de carácter espiritual, como la virtud, el honor, la honestidad, la amistad u otros valores, tenemos un sufrimiento interior. Este dolor, también denominado tristeza, incide particularmente sobre el pathos humano y acapara también los sentidos y la capacidad de gozar, de amar y de conocer. Cuando el bien que perdemos, en cambio, es de carácter físico, como es el caso de la parálisis, entonces el sufrimiento es doble: es exterior, por causa de la materia, 
es decir, de los sentidos que experimentan la privación de una forma violenta, y además es interior, ya que los sentidos se refieren al espíritu. El hombre tiene la capacidad de reflexionar y meditar sobre su dolor físico. El sujeto se preocupa por su futuro y por las consecuencias que comportará un determinado mal. Por tanto, el mal físico tiene una doble incidencia, a nivel de sentidos y a nivel reflexivo, espiritual.

\section{El anhelo de plenitud}

La segunda causa del dolor que nuestro autor analiza es la concupiscencia. Pero, ¿Qué es la concupiscencia? Santo Tomás dice que es un movimiento del apetito hacia el bien (concupiscentia autem est motus quidam appetitus in bonum) (I-II q. 36 a. 2). En efecto, la concupiscencia es el deseo de posesión de bien, el movimiento del apetito hacia el bien, la tendencia del agente hacia el bien. Toda criatura por el mero hecho de serlo es concupiscente, en la medida en que tiende hacia el bien y desea abrazarlo y gozarlo.

Santo Tomás asume la idea de san Agustín de que la concupiscencia es la causa universal del sufrimiento. El hombre, como toda criatura del universo, anhela el bien, anhela poseerlo, tenerlo, gozarlo. Este deseo le inclina hacia el bien y por consiguiente, repudiar el mal contrario. El principio de este movimiento apetitivo es el amor, que es la primera inclinación del apetito a alcanzar el bien. El bien es la causa objetiva del amor en su concepción más amplia, dado que actúa como causa final: el amor siempre se dirige hacia un bien, ya que el bien es el objeto per se del amor. El bien y la perfección son el motivo y el objeto del amor, pero no solamente en el sentido que todo ser tiene la inclinación natural a adquirir o conservar el propio bien, sino que bondad o perfección de un sujeto puede ser también para él su razón de amar, en la medida en que los seres tienen la tendencia a difundir el propio bien comunicándolo a los otros.

Ahora bien, el hombre no siempre alcanza el bien. Hay dificultades, trabas, fronteras que ponen en peligro la satisfacción del anhelo, la plenitud del amor. Todo lo que priva esta culminación del deseo, todo lo que se interpone en el camino de la plenitud, causa sufrimiento y entristece el espíritu.

Así lo expresa santo Tomás con fineza intelectual: "Pero la misma concupiscencia, considerada según su propia razón de ser, a veces es causa de dolor. En efecto, todo lo que impide que el movimiento alcance su término es contrario al movimiento. Y todo lo que es contrario al movimiento del apetito entristece. Por consiguiente, la concupiscencia se convierte en causa de la tristeza, en la medida en que nos entristecemos por la tardanza del bien anhelado o por su total supresión». (I-II q. 36 a. 2).

A pesar de esto, santo Tomás considera que la concupiscencia no puede ser la causa universal del sufrimiento, ya que nos duele más la desaparición de los bienes presentes, en los que ya encontramos placer, que no en los futuros, que anhelamos. En este sentido, tiene razón Juan Damasceno, cuando dice que la concupiscencia no es causa de tristeza ni de dolor porque el dolor se refiere al presente, mientras que la concupiscencia se refiere al futuro (Fide Orth. 2, 12). Santo Tomás responde diciendo que lo que ansiamos, aunque sea futuro, ya es presente en un cierto sentido, en la medida en que es esperado. También se puede decir que, aunque el bien anhelado sea futuro, existe un impedimento.

\section{EL PESO DEL SUFRIMIENTO}

Hemos visto, en el capítulo anterior, las diversas causas que motivan el sufrimiento. A continuación estudiaremos los efectos del dolor en el sujeto que lo sufre. El dolor tiene una implicación importante en la vida de la persona. No es un fenómeno accidental ni pasajero, sino que acapara integralmente al sujeto. El dolor deja mella en el alma de la persona que lo ha vivido La persona se ve afectada por el dolor, se ve alterada tanto a nivel interior como exterior, tanto en el ámbito intrapersonal como en el espacio interpersonal.

Hay diferentes grados y tipos de sufrimiento. El dolor puntual no tiene la misma incidencia ni los mismos efectos que el 
dolor que sufre el enfermo crónico postrado en una cama de hospital. Tampoco es simétrico el dolor que sufre una madre que ha perdido a sus hijos con el de un herido de guerra. A pesar de esta diversidad tan extendida, cabe decir que todo dolor, por débil que sea, tiene unos efectos determinados. Los efectos crecen en proporción al grado y a la intensidad del dolor. Aún así, hay que tener en cuenta que cada persona es un mundo, y que reacciona de una forma propia y específica frente al misterio del sufrimiento.

Aún admitiendo que hay distintos grados de sufrimiento, y que cada persona lo vive de una forma única y singular, es lícito extrapolar los efectos globales que causa el sufrimiento en la persona humana. Es lícito si tomamos la debida cautela y si aceptamos de entrada el margen de error que conlleva implícita la generalización.

El sufrimiento cambia las personas, hace variar los comportamientos, los hábitos, los sentimientos, y sobre todo, la concepción del mundo y de la vida. El sufrimiento marca una línea divisoria, marca una frontera entre el antes y el después. Nadie permanece igual después de haber sufrido gravemente.

Hemos distinguido el dolor interior del dolor exterior, con anterioridad. El primero incide en el espíritu, el segundo hace referencia en algún miembro del cuerpo, en alguna parte de la naturaleza física de la persona. Los efectos del dolor exterior son muy diversos y dependen de factores fisiológicos que la medicina trata de poner de manifiesto.

Nosotros nos centraremos en los efectos del dolor interior, es decir, la tristeza, que es lo que afecta a la interioridad de la persona, su espíritu.

Dentro de este ámbito, podríamos distinguir dos clases de efectos: unos efectos inmediatos o primarios y unos efectos mediatos o secundarios. Los primeros son aquellos que van íntimamente asociados a la experiencia del dolor. Los segundos, en cambio, son posteriores, son fruto de la reflexión y la meditación sobre la experiencia vivida.

Siguiendo el planteamiento de santo Tomás, se pueden enumerar los efectos inmediatos del dolor de la siguiente forma: el dolor acapara el ánimo, debilita toda actividad, disminuye la capacidad de aprender y perjudica el cuerpo más que cualquier otra pasión (S. Th., I-II, q. 37).

Dice santo Tomás que la tristeza se produce a causa de un mal presente, que, por el mero hecho de oponerse al movimiento de la voluntad, acapara el ánimo en la medida en que le impide disfrutar de lo que quiere. El dolor interior, la tristeza, pesa sobre el ánimo como una lápida de mármol, aplasta psicológicamente a la persona, la deja sin ánimo, sin ganas de hacer nada. La tristeza quita energías e introduce a la persona en un estado de apatía, de desgana y de hundimiento espiritual. Nada le importa, nada tiene importancia, todo es indiferente. Quien está triste no tiene iniciativa, ni fuerza, ni puede tomar decisiones, ni se arriesga a emprender ninguna acción. Quien está triste está muerto por dentro y por fuera, y queda encerrado en su mundo, en su pena, encerrado como si habitara dentro de una fortificación.

El dolor interior, que con frecuencia es reflejo de un dolor exterior, conduce al sujeto a la tristeza. Como dice santo Tomás, "la tristeza consume al hombre, cuando la fuerza del mal entristecedor afecta completamente al hombre, de tal manera que quita toda esperanza de huir de él. De esta forma acapara a la vez que consume" (Ibidem). En efecto, la tristeza aumenta en la medida en que disminuye la esperanza de huir del mal. Cuanto más intenso y duradero es el dolor, más profunda y sentida es la tristeza. Si la fuerza del mal crece, hasta tal punto que quita cualquier posible esperanza de huída, entonces el impulso del alma angustiado encuentra tantas dificultades que no puede explayarse en nada. Cuando esto sucede, la persona se halla completamente desanimada.

\section{LA TRISTEZA}

El primer efecto del dolor interior o tristeza es, pues, el agobio del ánimo. Otro efecto íntimamente relacionado con éste es el debilitamiento de cualquier tipo de actividad. Como dice Aristóteles en su Metafísica, el hombre es un ser que puede 
realizar tres tipos de actividades: teorético-especulativa (teoría), práctica (praxis), y productiva (poiesis). La tristeza debilita la actividad, sea de naturaleza estrictamente teorética o sea de naturaleza pragmática.

Quien sufre, paraliza su actividad, su dinámica vital. Tiende a instalarse y a quedarse quieto. De hecho, la tristeza se opone al motor que nos fuerza a realizar una determinada actividad. Así lo explica santo Tomás: "La tristeza es un impedimento para cualquier actividad, ya que lo que hacemos tristes, nunca lo hacemos tan bien como lo que hacemos con placer o sin tristeza. La razón es que la voluntad es la causa de la actividad humana y, por tanto, cuando la actividad tiene por objeto algo entristecedor, necesariamente la acción se debilita».

En efecto, la voluntad es el motor de la actividad humana. Si la voluntad está alterada por la tristeza, si está desencantada a causa de un mal que afecta al sujeto, entonces su potencialidad también disminuye, y por tanto, pierde ímpetu. Por este motivo, el dolor debilita toda actividad.

Si el sufrimiento disminuye toda actividad, entonces también disminuye la actividad intelectual, la comprensión de la realidad, de uno mismo y de los otros, la capacidad de aprender cosas nuevas. El dolor sensible atrae hacia sí la intención del alma. El espíritu queda focalizado frente al dolor. El sufrimiento monopoliza a la persona y la arrastra hacia él. Los otros puntos de interés, sean de carácter teórico o práctico, se difuminan en el horizonte de la conciencia, de tal manera que el sujeto solamente presta atención al dolor que sufre. En estas circunstancias, el hombre no está habilitado para comprender nada, para entender nada. No está capacitado para hacer el esfuerzo que implica conocer algo nuevo. El sufrimiento puede ser tan intenso que puede impedir, incluso, meditar sobre lo que ya se sabe.

En este punto se dan diferentes actitudes. El hombre que siente un gran anhelo por saber, que siente un intenso amor por la sabiduría, podrá dominar con más soberanía la pesadez del dolor y desarrollar algún tipo de actividad. Aún así, hay que reconocer que el dolor, como tal, absorbe la capacidad de aprender.

El sufrimiento interior perjudica al cuerpo más que otras pasiones. Existe una relación entre el dolor espiritual y el funcionamiento del cuerpo. La tristeza afecta también a la corporalidad de la persona, influye en la dinámica del cuerpo. La persona no es una unión accidental y periférica de dos sustancias aisladas (res extensa y res cogitans) como piensa Descartes, sino la unión sustancial entre cuerpo y alma. Prueba de ello es que un dolor interior perjudica al cuerpo más que cualquier otra cosa.

Así lo explica santo Tomás: "De entre todas las pasiones del alma, la tristeza es la que más daña al cuerpo. La razón es que la tristeza se opone a la vida humana, contrariando lo que de específico tiene el movimiento vital y no, como hacen las otras pasiones, contrariándolo cuantitativamente. En efecto, la vida humana consiste en un cierto impulso que, partiendo del corazón se extiende a los otros miembros; impulso que pertenece a la naturaleza humana en una medida determinada. Si este impulso excediera la medida adecuada, se opondría a la vida humana, contrariándola cuantitativa, pero no específicamente. Pero si se opone a la realización de su impulso, la contrariaría en lo que tiene de específico".

La tristeza se opone a la vida humana, contrariando lo que tiene de específico. Apacigua el impulso vital, el deseo de existir, de ser, de conocer, de amar, de gozar de los sentidos. La tristeza o el dolor interior son un estado que frena el deseo vital. A un hombre triste le es igual vivir que morir. Cuando la tristeza es muy grande, la persona cae en la desesperación.

\section{LA DESESPERACIÓN}

La desesperación es un efecto mediato del dolor interior ( $S$. Th. I-II q. 24 a. 2). En una primera instancia, la persona confía que aquel mal que le afecta será eliminado con la ayuda de los fármacos, si se trata de un dolor físico, o a través de los amigos, si el dolor es de cariz espiritual. Cuando el mal persiste a lo largo de una temporada, o aumenta de tono, las esperanzas dismi- 
nuyen y la desesperación gana terreno. La desesperación es la privación de toda esperanza. El hombre desesperado es aquel que ha perdido toda confianza en el futuro y cree que no saldrá del pozo en el que se halla.

Por tanto, el sufrimiento alcanza las cotas más altas de expresividad en la figura del desesperado. Quien se desespera, lo ha perdido todo. Ha perdido, incluso, la poca salud que le quedaba, el calor de los amigos y el sentido de su vida. Desesperarse frente al dolor crónico es una reacción humana, propia y exclusivamente humana. El animal no es capaz de avanzar el futuro, no tiene capacidad prospectiva. La persona que sufre una enfermedad crónica imagina su futuro y su futuro dolor, y por ello cae en la desesperación. La negrura que ve le angustia, le desconcierta, le condena a la amargura.

La desesperación es, pues, una particularidad de la persona humana íntimamente ligada a su espiritualidad. Pero la desesperación, como el dolor interior y exterior, tiene remedios. El hombre es capaz de sobreponerse al dolor. Contra la desesperación existe la virtud de la esperanza, de la fortaleza y la grandeza de la perseverancia. No todo está perdido para quien sufre un dolor crónico, para quien ve pasar los días de su vida dentro de las paredes de un hospital. El hombre tiene capacidad para enfrentarse al dolor $\mathrm{y}$ superarlo.

Superarlo no significa eliminarlo, sino aprender a convivir con él y tutelarlo desde la racionalidad y el sentimiento. El dolor existe y, en muchos casos, continuará existiendo. Frente a él, existen dos opciones: la desesperación que conduce a la amargura, al desánimo, y al aislamiento, o la convivencia con él a través de la aceptación. Aceptarlo no significa resignarse, sino situarlo dentro de los límites que le pertenecen. Pero, ¿cuáles son estos límites, estas fronteras? Con frecuencia el dolor traspasa su ámbito de acción e invade toda la conciencia. La persona que sufre este dolor queda bloqueada. Es incapaz de ver nada, es incapaz de objetivar y de analizar las posibilidades de salida. El dolor enclaustra y satura.

\section{SUFRIMIENTO Y SER PERSONAL}

Pero la persona es mucho más rica que el dolor que sufre. Ontológicamente hablando, la persona es la criatura más perfecta de la creación, la criatura más digna y más noble (S. Th., I q. 29 a. 3c). A través del espíritu participa con más intensidad y gravedad del ser, de la realidad. Desde este punto de vista, el dolor es claramente inferior. La tristeza, que no es otra cosa que la percepción subjetiva del mal, tal y como hemos visto con anterioridad, no tiene ser propio sino tomado prestado de otro. Por esto su naturaleza es incomparablemente más débil y frágil que la de la persona. Aún así, su presencia tiene un alcance y una influencia muy graves.

El sufrimiento afecta a la globalidad del ser humano, y le deja conmocionado. A pesar de esto, la experiencia nos muestra que personas que han sufrido grandes dolores a lo largo de su existencia han sabido sacar el máximo rendimiento de su vida, han sabido convivir con este inquilino incómodo y situarlo en la esfera que le pertenece. No hay ninguna duda de que el dolor es una privación, es una contrariedad. Pero la persona es mucho más rica, mucho más fuerte, y plena que el mal, porque participa del ser con más intensidad, con más penetración ontológica.

Desde el punto de vista metafísico, pues, la persona tiene la posibilidad de vencer al dolor y sobreponerlo. El ser es superior al mal, dado que el mal depende totalmente del ser. Allí donde hay mal, hay también ser, porque el mal arraiga en el bien, y el bien en el ser. Por tanto, una persona puede sufrir un determinado dolor, corporal o interior, pero en la medida en que es, en la medida en que tiene ser, entonces tiene más bien que mal, tiene más perfección que imperfección. Puede ocurrir que sufra una determinada imperfección y, por tanto, que esté tomada de una forma o de una actualidad. Ahora bien, si es, si tiene presencia real en la existencia, entonces participa del ser, y por tanto, tiene la máxima perfección de todas, la forma de todas las formas (De potentia, q. 1 a. 7 ad 9).

Desde este punto de vista, no hay ningún mal que elimine totalmente el bien del 
ser. Psicológicamente el mal puede aminorar el instinto vital de una persona, pero de ninguna manera puede reducirlo a la nada. La cultura popular se ha hecho eco de esta verdad ontológica a través del adagio: "Mientras hay vida, hay esperanza». En efecto, mientras hay ser, mientras haya algo, entonces hay perfección, hay unidad, bondad, belleza y verdad. El mal hunde sus raíces en el bien, y sólo en el bien puede hacerse presente. Pero su presencia no es otra cosa que ausencia de bien. Es una presencia ausente.

La persona, aunque esté faltada de la perfección que por naturaleza le pertenece, como puede ser un órgano corporal, es la criatura más digna de la creación, la más bella, la más noble y la más buena. La persona que sufre tiende a infravalorarse, a empequeñecerle y a contemplarse en su miseria. Ocurre una extraña operación sicológica, por la que el enfermo siente una satisfacción en la insatisfacción, una autocomplacencia en el dolor. De esta forma, la persona se hunde cada vez más en su cueva y adopta un comportamiento alegre y rencoroso. No quiere la ayuda de nadie, ni de los familiares, ni de los amigos, ni de los analistas.

Hemos visto que desde el punto de vista ontológico, el hombre puede superar el sufrimiento. Tenemos las bases aseguradas, pero ¿cómo es posible hacerlo realidad? ¿Cómo es posible realizar esta operación? ¿Qué mecanismos tiene la persona humana para fortalecerse frente al sufrimiento y tomarle medidas?

No es cierto que todo el sufrimiento pueda ser barrido en su totalidad gracias a los métodos de la ciencia. El hombre no es un simple autómata. Su dolor no se reduce única y exclusivamente a un dolor orgánico. También es espíritu, y en tanto que espíritu, puede sufrir espiritualmente. Las utopías materialistas y mecanicistas han plasmado un ideal de humanidad vacío de espiritualidad, un ideal que de ninguna manera se corresponde con la realidad de los hechos. Hombres perfectamente ajustados desde el punto de vista orgánico, sufren intensos sufrimientos que la ciencia experimental no puede curar. Este hecho prueba que el hombre necesita también otros elementos para combatir el dolor y superarlo. 
